\title{
The Application of a New Research and Development Project Selection Model in SMEs
}

\author{
C. P. Lawson, P. J. Longhurst and P.C. Ivey
}

Cranfield University

Cranfield

UK 


\title{
The Application of a New Research and Development Project Selection Model in SMEs
}

\begin{abstract}
The work reported in this paper investigates Research and Development (R\&D) project selection models, focusing on the application of a new hybrid project selection model in a United Kingdom based engineering Small to Medium-sized Enterprise (SME). Work is done to enable the new project selection model to be applied in an SME and the model is then field tested. field test results provide insight into the barriers to the adoption of such a model in an SME, either as a decision support tool or as a knowledge acquisition and learning tool. As an outcome of the field test results a simple R\&D project portfolio cash-flow tracking method is proposed.
\end{abstract}

\section{Introduction}

The need to innovate is viewed by many companies as central to their survival strategy. Novel and high-tech product development is an effective way to give companies a leading edge over competitors and open new markets. Having a product of technical superiority in the market place can be a significant advantage. Hence the high importance of good research and development for firms involved in technological products.

Research and Development (R\&D) is an ongoing process for forward thinking technologybased companies. Development of existing products is advisable to keep ahead of advances that competitors may be making. Further, when a potential customer approaches a firm outlining its requirements for a product, $R \& D$ may be required to fulfil the request. More speculative 'blue sky’ research is also an option for firms. Speculative R\&D is a valuable avenue to open new market opportunities and this type of research may lead to totally new products being developed, new markets being entered and thus strengthen the company's position through diversification.

Where a firm seeks to define the balance between R\&D in established areas of corporate knowledge and more speculative $R \& D$ a decision has to be made on how to prioritise investment. A choice exists between investing in development within proven markets and product spheres or venturing into new knowledge domains. The situation is analogous to a fleet 
of fishing trawlers. While most of the fleet will trawl waters known to be frequented by fish, a few boats may speculate by exploring uncharted waters. This can lead to new opportunities being discovered and thus reducing the fleet's dependence on its familiar areas for catches. Similarly, a technology-based company may guard against being damaged by downturns in its established sectors by seeking new sectors to move into through speculative ‘blue sky’ R\&D.

Large numbers of proposed R\&D projects may potentially be pursued when considering this R\&D philosophy. The ability to consistently select the best projects to fund is therefore vitally important to firms. Extensive academic research has been conducted over the past thirty-five years or so to produce methods to improve the R\&D project selection processes. Many project selection models have been developed over the years taking into account projects' financial aspects, risk considerations, or ranking projects by using scoring models. Research has shown (Cooper et al., 2001) that the most successful approach is to select projects by considering financial, risk and project ranking, using a so-called hybrid selection model.

Despite this scope of previous work, relatively little research has been done to investigate the application of project selection processes within companies, particularly in small firms. This study looks at an individual case of applying a hybrid R\&D project selection model within a small engineering company. Such a field test provides an insight into the practicalities of applying a model abstracted from academic research in industry. Insight is also gained into the R\&D selection process currently used within a small UK based engineering firm. From this study the factors that determine whether or not such a project selection model is likely to be adopted within a particular company are analysed based on the field test results and reviewed literature.

\section{Research Project Selection Model}

When an organisation is tasked with deciding which research projects to proceed with, and which projects to reject, the selection process is often inconsistent. This research programme was designed to test the provision of a more formal, consistent and logical management tool to assist in project selection. This work builds on the findings of previous research at Cranfield University (Smout, 1995, Ferguson, 1997, Lockwood, 1999, Coldrick et al, 2002). The test 
focuses specifically on the requirements of R\&D managers in Small and Medium-sized Enterprises (SMEs).

A research project selection model has been developed by Smout, 1995, Ferguson, 1997 and Lockwood, 1999 and is used to form the basis for this work. The previous work has concluded that the hybrid PSM is the type that will produce best results. This previous work has resulted in a theoretical and accademic model, as such work has been done in this programme to facilitate the application of this model in an SME. The results reported are of a field test at a small engineering company in the aerospace instrument and telecommunications sectors and the conclusions are drawn on the applicability of such selection models within small companies.

\subsection{Use of Project Selection Models in Industry}

Despite the fact that many models for R\&D project selection have been developed by academics, very few seem to have been tested in companies. Similarly, relatively little research has been published on the project selection techniques that are actually used in companies. There are a limited number of surveys that have been published into methods being employed in large firms (Cooper et al., 1997a, 1997b). These surveys are largely based on manager's experiancesand are reviewed in the remainder of this section. There is no such information widely available on techniques being used in SMEs. In the absence of statistics on the application of project selection models in small firms, attention is turned to surveys of methods used in large companies to gain insight. Therefore, this study focuses on R\&D in SMEs, and consequently provides novel insights currently lacking in the published literature.

Large firms in the USA that are proven successes in R\&D activities have previously been surveyed to establish the management practices they use (Matheson et al., 1994; Menke, 1997a, 1997b). Financial methods of project selection have been found to be the most widely used amongst large firms. However, companies that employ formalised project selection techniques that incorporate risk analysis and a scoring model as well as financial analysis generally outperform companies that rely solely on considering the financial aspects of projects (Cooper et al., 2001). 
Ongoing research at McMaster University, Canada (Cooper et al., 1999, 2000, 2001), has surveyed over three hundred large companies throughout the world on their R\&D portfolio management methods. From this, businesses have been sorted into four clusters based on the quality of their portfolio management technique and whether or not management is satisfied with the current method used. These clusters were identified using cluster analysis (Cooper and Kleinschmidt, 1995) and their definitions are illustrated below in the Table 1.

\begin{tabular}{|l|ccccc|}
\cline { 2 - 5 } \multicolumn{1}{c|}{} & \multicolumn{4}{c|}{ Cluster } \\
\hline Classification Criteria & Benchmark & Crossroads & Duds & Cowboys \\
\hline \hline Good portfolio management technique? & Yes & Yes & No & No \\
\hline Technique fits management style? & Yes & No & No & Yes \\
\hline
\end{tabular}

Table 1 - Company Classification by Portfolio Management Technique and Their Management's View of the Technique Used.

As expected, 'Benchmark' companies were found to perform best in terms of R\&D project success, with 'Crossroads' second best. An interesting finding is that 'Duds' outperform 'Cowboys' (Cooper et al., 1999). This suggests that if a company has poorly structured research portfolio management, it is at least better if management are dissatisfied with this state of affairs.

Applying a structured and formal method of managing portfolio has been found to have several benefits. The balance of projects is improved, as is the number of projects in a firm's portfolio. Also, more projects are completed on time and R\&D spending better reflects company strategy when good quality portfolio management techniques are used (Cooper et al., 1998).

Surveys have shown that companies that employ formal project selection methods have better project launch success than those companies with no formal project selection technique. Sales and profit objectives have also been found to be significantly better where structured selection techniques are used (Cooper et al., 2000).

Reports on in-house R\&D management techniques used within the companies SEI of Japan and ABB show that formal documented portfolio management techniques are utilised successfully in these large firms (Osawa and Murakami, 2002; Stillman, 1997). 


\subsection{New Project Selection Model Study}

The project selection model, developed by Lockwood (1999) is intended for use as a tool to assist the engineer or manager to select the best project or projects from those put forward for consideration. The model does not set out to establish the best portfolio mix of research projects. It is designed to assess projects on their own merits, and to compare projects of similar types with each other.

Project selection models have historically fallen into three categories, financial, risk and scoring. The model studied here can be considered as a hybrid, composed of the three distinct and established project selection techniques. A scoring model is incorporated into the model, as is risk analysis and assessment. Financial considerations are also included in the form of Cost Benefit Analysis (CBA) or Discounted Cash Flow (DCF). When used as a selection tool the model is designed to be applicable to all types of research projects, but cannot be used to compare projects of different types. Three project type definitions are used, namely; Basic Research, Applied Research and Experimental Development. The model uses an initial evaluation stage to quickly establish if a project shows potential and therefore merits a more detailed examination. This evaluation is qualitative and is in essence a scoring model. Quantitative and qualitative project criteria are set out. Scores are weighted and summed to give a single figure result. By weighting, the significance of each criterion and category are taken into account. The process by which the scores and weights are arrived at is vitally important in applying the model successfully. This process is discussed in detail in section 2.3.

The project selection stages provide a more rigorous examination by conducting risk assessment and analysis on those projects that give promising results in the initial evaluation stage. Cost Benefit Analysis or Discounted Cash Flow is also applied to analyse the financial aspects of proposed projects.

A rigorous set of field tests within companies of various sizes is essential to assess the applicability of the model. Whereas, a study of previous work shows that the model is yet to be tested at first hand. It is therefore necessary to conduct further work to allow the model to be applied in real companies. 


\subsection{Application of the Project Selection Model}

In the previous section a need to validate the model in real firms was identified. In section 2.1 a distinct lack of documented evidence testing model usage in SMEs was highlighted. Therefore, this section details work done with the model to enable its application in a field test within a small engineering company in the telecommunications and aerospace sectors. A study of the project selection model allowed documents to be produced that enabled the model to be applied at the company. A step-by-step guide to model application has been developed. The process is represented diagrammatically in Figure 1. Instructions and guidelines illustrating how to carry out each step have also been produced.

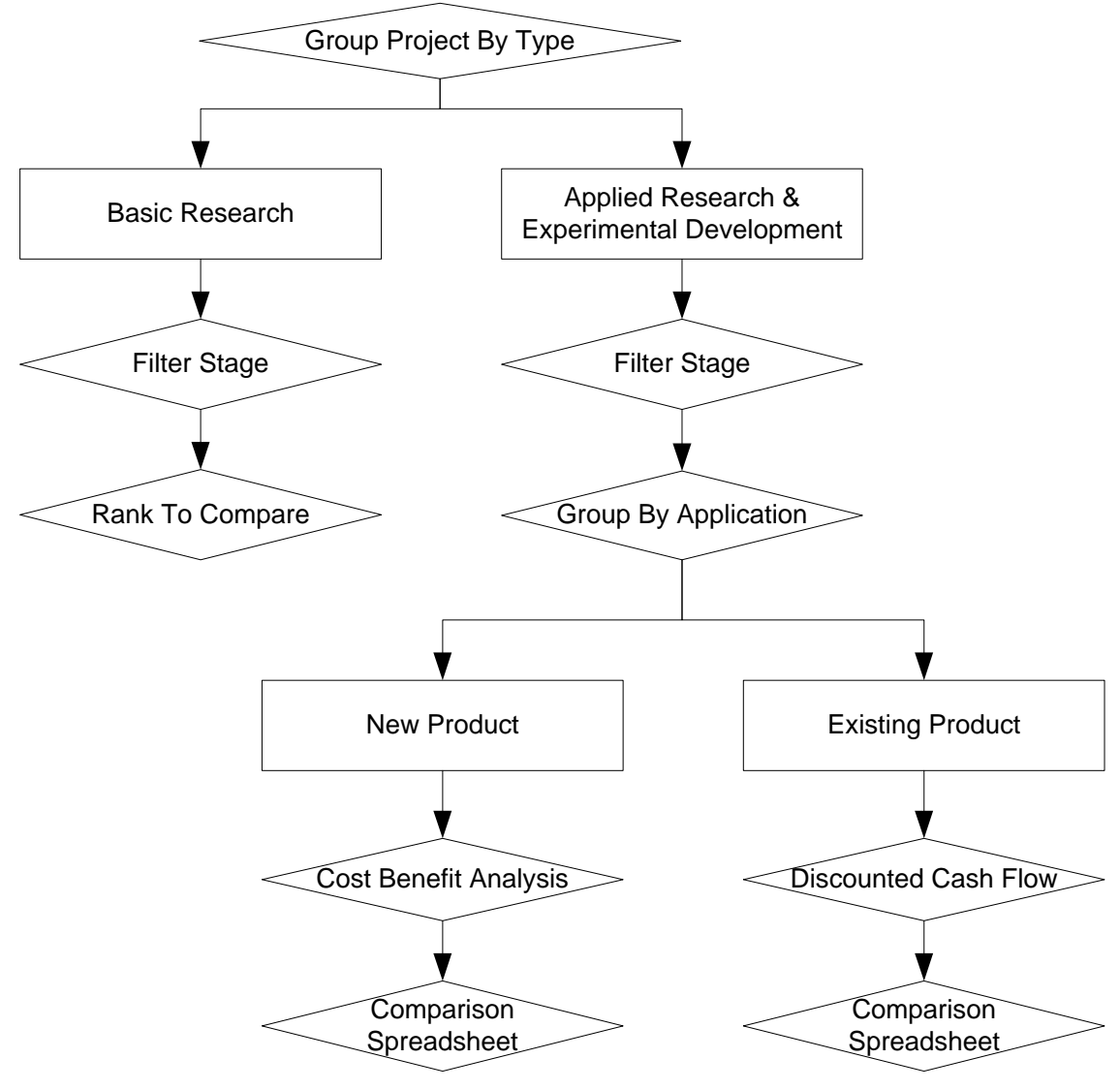

Figure 1 - Project Selection Model Step-By-Step Flow Chart

Since the project selection model is applicable to all types of research projects, but cannot compare projects of different types, the first step in using the model is to categorise the project either Basic Research or Applied Research and Experimental Development. Information on how to categorise a project is shown in Figure 2. However, the nature of the field test company's business means that they do not undertake Basic Research projects. 


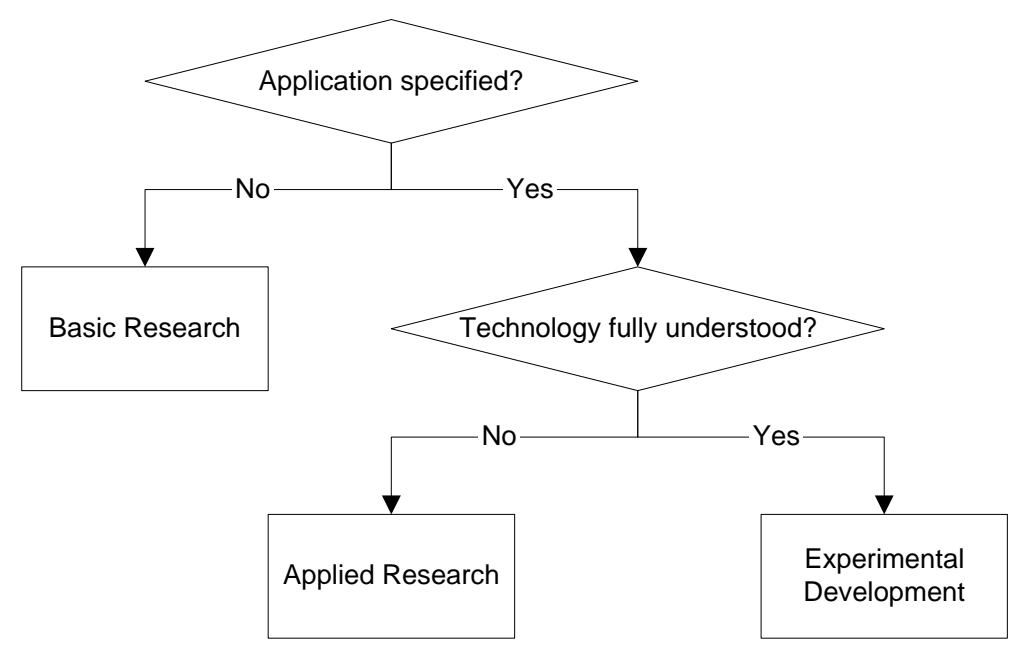

Figure 2 - Project Selection Model Project Type Classification Flow Chart

Once a project has been classified, a simple evaluation is carried out. This 'Filter' stage determines if the project can quickly be rejected as obviously being unpromising. The model suggests using six industry wide categories, consisting of company standard criteria. An example of such a Filter stage suitable for use within the company can be seen in Table 2 . 


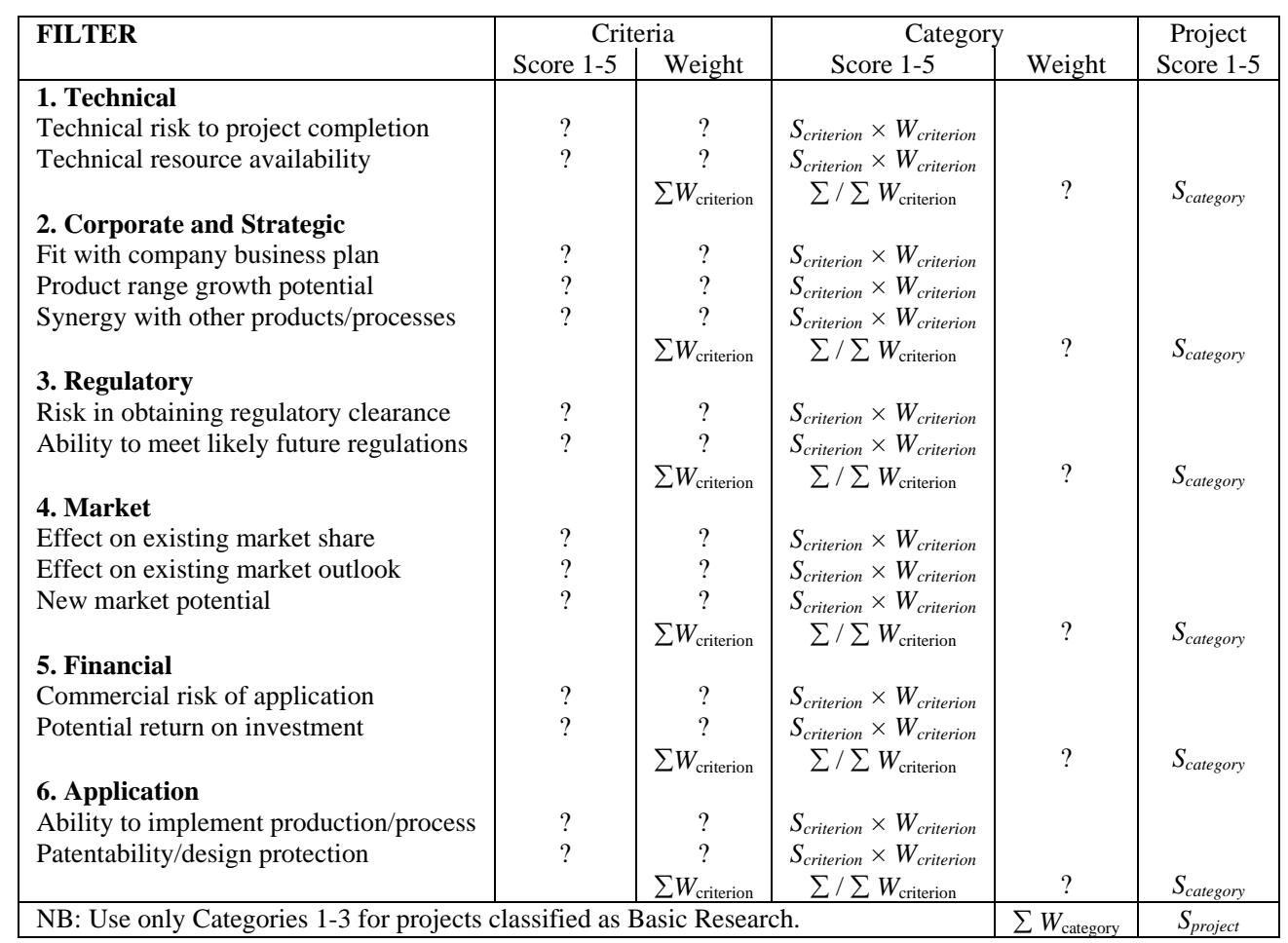

Table 2 - Project Selection Model Filter Stage

Guidance is provided on score and weighting assignments. Scores assigned in the Filter stage should be established by standard group decision-making techniques. This could be by Normal Group Technique (NGT), where an anonymous ballot is followed by a discussion of the scores. A second ballot is then averaged to establish the final score. Alternatively, Delphi technique can be used; this is a remote survey with no group interaction.

Further consideration of the application of the model assumes that the proposed project is not of classification Basic Research. As previously mentioned, the company being used in the field test does not undertake projects of that type.

Applied Research or Experimental Development projects that score sufficiently well in the Filter stage are next put forward for more detailed consideration. Further project classification is required as New Product projects (generally Applied Research) cannot be compared with 
Existing Product projects (generally Experimental Development). Once classified, projects can be ranked by their scores from the Filter stage.

For both types of project (New Product and Existing Product) the next stage is to conduct a Risk Assessment. This assessment establishes the appropriate level of risk analysis with which to scrutinise the proposed research project. This is done by finding a value ' $x$ '. $x$ is determined by considering available resources, budget and Benefit Cost Ratio. The equation for determining $x$ can be seen below.

$x=R \cdot r+B \cdot b+\frac{a}{B C R}$

$r+b=1$

Where: $R$ is manpower resource. (1-5)

$r$ is the resource weighting factor.

$B$ is the project budget. (1-5)

$b$ is the budget weighting factor

$a=0.01$. A weighting factor to reduce the importance of BCR

$B C R=($ Benefits - Total Cost $) /$ Total Cost

Assigning values to the variables in the $x$ equation should follow a consistent method. A single table should be constructed to assess the budget and manpower resources required for the range of projects being considered for approval. Once values are assigned to the variables the value of $x$ can be calculated, consequently the level of risk assessment corresponding to the calculated value of $x$ is known. The process is illustrated in Figure 3. 


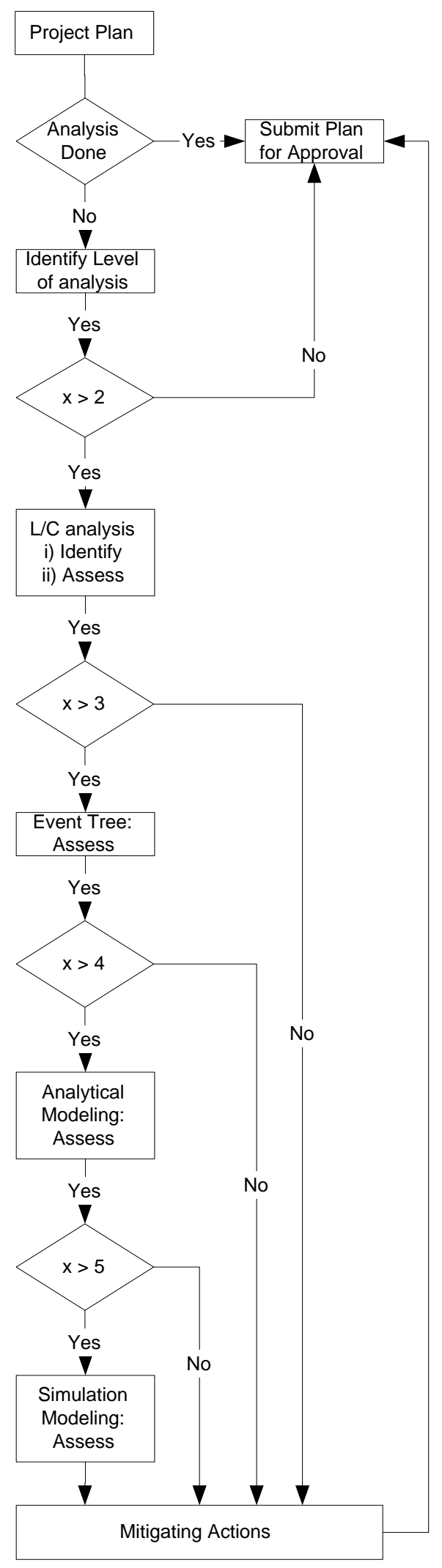

Figure 3 - Risk Analysis Flow Chart 
After the suggested level of risk analysis is carried out mitigating action is taken in an attempt to reduce the chance of the project failing to meet expectations. The process then repeats from the risk assessment stage until either the risk is sufficiently low to approve the project, or it is the case that all mitigating action has been taken and the project is still deemed to risky to approve.

For projects that pass the risk analysis stage the next stage in the selection process depends upon the project's classification. A Cost Benefit Analysis should be conducted next for projects classified as New Product, while a Discounted Cash Flow study is the next stage for Existing Product projects. For an existing product cash flow information can be judged, hence the more informative DCF analysis is chosen over CBA. For a new product, cash flow information is unlikely to be able to be predicted with any degree of confidence, hence CBA techniques are used for financial analysis.

Finally, in all cases is a Comparison Spreadsheet to allow selection between projects of the same type to be made. This brings together for review the scoring model scores, risk analysis results and financial assessment findings for a final comparison of the projects being considered for approval.

\subsection{Project Selection Model Field Test}

In order to gain insight into the model's potential for application within small engineering companies a project selection model field test was used with small UK-based engineering company. The firm operates in the telecommunications and instrumentation sectors and was chosen for its active role in $\mathrm{R} \& \mathrm{D}$ and product development. Work reported in previous sections has readied the project selection model for application at the company. This has been achieved by producing documents that can be used by management at the company being considered in the field test. These documents have been developed following the framework for a project selection model set out by Lockwood (1999).

The field test was facilitated by a meeting with a member of the company's senior management who was is in the position of making project selection decisions. The meeting allowed the project selection method developed in this research programme to be applied to a project 
previously undertaken by the company. Throughout the process of applying the project selection model feedback was gathered on all aspects of the model. Comparisons were drawn with the method used when the company originally considered the project for selection.

Investigations into the selection process at the company revealed that many of their normal considerations are reflected by those in the selection model. However, at the company the process is not explicit and is carried out by an individual. As such no data is recorded.

Management at the company argue that the quality of decision making within the company is maintained without the use of a project selection model. Good decision making employees continue to consistently make good decisions, while bad decision makers are dismissed from the company.

Therefore, the field test found that the model would not be used for decision making within the company. Indeed it has been suggested before that management are unlikely to actually use formal models such as this for decision making (Moore and Baker, 1969). In fact, this was found to be the case at the company being considered here.

In place of a research selection role, the possibility exists to instead use the model as an information tool. In this case application of the model aids communication of decision making information down from senior management to project leaders. Management at the company considers that the value gained by using the model for this reason is outweighed by the cost of its implementation. This cost was estimated to be fifteen thousand pounds per annum, as an additional staff member would be needed to administer the decision making records.

One aspect of the project selection model is considered by the company to be potentially worthwhile to formalise and document. The financial analysis section of the model allows documented Discounted Cash Flow to be linked to technical and financial project targets. The next section will therefore look at developing a project finances tracking framework that meets the company's requirements of being quick and easy to apply. 


\section{Multiple Project Cash Flow Tracking}

The research project selection model field test has shown that such a formalised and documented management tool is unlikely to be implemented within the small engineering company tested. A need has been identified to enable management to closely track the cash flows within the company's portfolio of projects.

While the financial department will have a good understanding of company finances from the accounting processes, engineering management at the company currently lack this insight. What would be beneficial is a method which will allow management to conveniently track individual project, as well as the overall cash flow associated with the company's entire portfolio of projects. The tracking method should also allow management to easily predict the cash flow consequences of a project running over the initially estimated time schedule and budget. This should then be mapped to the portfolio cash flow to see the overall impact on finances.

To fulfil this need a simple extension to establish Discounted Cash Flow analysis techniques is proposed. By presenting DCF analysis information in a particular way, projects' costs over time can be efficiently tracked by management. By individually tabulating DCF information for each project in the company's portfolio in a spreadsheet, the overall portfolio cash flow can be calculated and displayed both numerically and graphically. Changes can easily be made to individual investment figures and time scales. The impact for the project finances in the future, as well as the impact on the portfolio cash flow is then automatically calculated, with results displayed numerically and graphically. Table 3 shows a spreadsheet containing DCF for an example project. From a series of such project DCF tables a company's overall portfolio cash flow can be plotted as shown in Figure 4. 


\begin{tabular}{|r|r|r|r|r|r|r|r|r|r|r|}
\hline Calendar Year & 1990 & 1991 & 1992 & 1993 & 1994 & 1995 & 1996 & 1997 & 1998 & 1999 \\
Project Year & 1 & 2 & 3 & 4 & 5 & 6 & 7 & 8 & 9 & 10 \\
\hline Capital Investment & & & & & & & & & & \\
Research Costs & 0.7 & 8.3 & 4.5 & 4.0 & 0 & 0 & 0 & 0 & 0 & 0 \\
Consultancy Fees & 2.0 & 2.0 & 2.0 & 2.0 & 0 & 0 & 0 & 0 & 0 & 0 \\
University Fees & 1.5 & 1.5 & 1.5 & 1.5 & 0 & 0 & 0 & 0 & 0 & 0 \\
Labour Resource & 0 & 2.0 & 2.0 & 2.0 & 0 & 0 & 0 & 0 & 0 & 0 \\
Facility Investment & & & & & & & & & \\
Instrumentation & 0 & 0 & 0 & 0 & 230.4 & 230.4 & 230.4 & 230.4 & 230.4 & 230.4 \\
Re-building & 0 & 0 & 0 & 0 & 60.0 & 60.0 & 60.0 & 60.0 & 60.0 & 60.0 \\
Re-running & 0 & 0 & 0 & 0 & 128.0 & 128.0 & 128.0 & 128.0 & 128.0 & 128.0 \\
& & & & & & & & & & \\
Total Investment & 4.2 & 13.8 & 10.0 & 9.5 & 418.4 & 418.4 & 418.4 & 418.4 & 418.4 & 418.4 \\
\hline Capital Return & & & & & & & & & \\
\hline Preventing Damage & 0 & 0 & 0 & 0 & 768.0 & 768.0 & 768.0 & 768.0 & 768.0 & 768.0 \\
Total Return & 0 & 0 & 0 & 0 & 768.0 & 768.0 & 768.0 & 768.0 & 768.0 & 768.0 \\
\hline Net Cash Flow & -4.2 & -13.8 & -10.0 & -9.5 & 349.6 & 349.6 & 349.6 & 349.6 & 349.6 & 349.6 \\
Tax Effect @33\% & 1.4 & 4.6 & 3.3 & 3.1 & -115.4 & -115.4 & -115.4 & -115.4 & -115.4 & -115.4 \\
Effective Cash Flow & -2.8 & -9.2 & -6.7 & -6.4 & 234.2 & 234.2 & 234.2 & 234.2 & 234.2 & 234.2 \\
Cumulitive CF & -2.8 & -12.1 & -18.8 & -25.1 & 209.1 & 443.3 & 677.6 & 911.8 & 1146.0 & 1380.3 \\
Disc. Factor @16\% & 1.000 & 0.862 & 0.743 & 0.641 & 0.552 & 0.476 & 0.410 & 0.354 & 0.305 & 0.263 \\
NPV (real) & -2.8 & -8.0 & -5.0 & -4.1 & 129.4 & 111.5 & 96.1 & 82.9 & 71.4 & 61.6 \\
& & & & & & & & & \\
\hline
\end{tabular}

Table 3 - Discounted Cash Flow: Example Project 


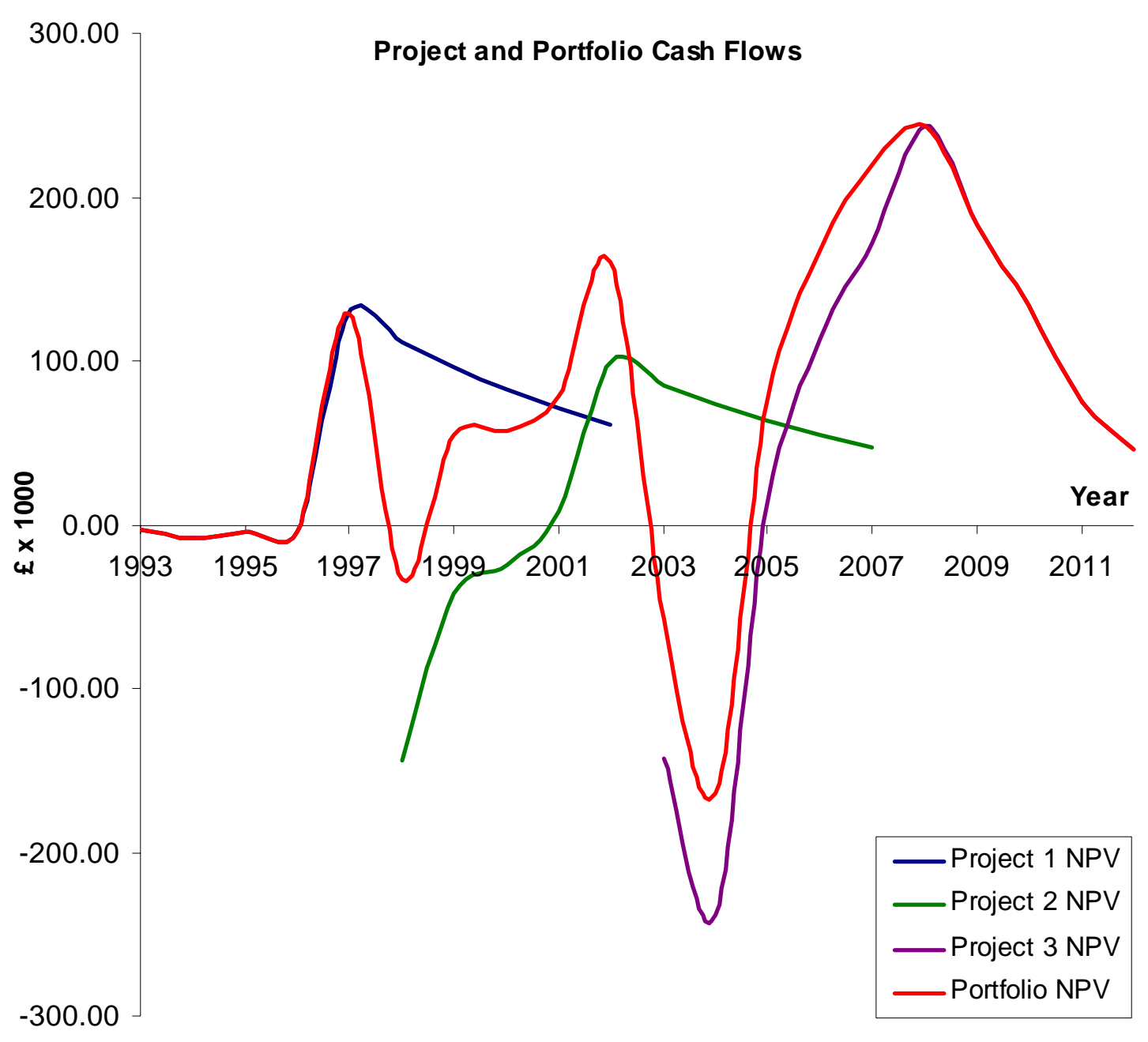

Figure 4 - Example Portfolio and Project Cash Flows Chart

\section{Summary and Conclusions}

The potential benefits of consistent and structured $R \& D$ project selection have long been recognised in both academia and industry. For about the last thirty-five years countless models have been developed to provide logic and structure to R\&D project and portfolio management. Early development centred on scoring and financial models. Risk assessment is also an established technique used in project evaluation. Much of the more recent work has produced hybrid selection tools, where the three aforementioned techniques, scoring, financial and risk are used to provide a more balanced project assessment tool. 
A particular new hybrid project selection model has been studied. A need to field test the model was identified. Consequently, work has been completed to allow translation of the model into an applicable form for a small engineering company. While documentation of project selection model development in academia and industry are widespread, reports of model evaluation and usage within industry are relatively scarce. While some studies have been conducted on model usage in large companies, applications within SMEs remain largely undocumented. This research has produced insights into the use of R\&D project selection models in SMEs by testing a recently developed hybrid project selection model in a UK-based engineering SME.

The field test conducted in this research at a typical small engineering firm points to a general conclusion that small companies are unlikely to adopt structured hybrid project selection models such as the model considered here. This is due to management's view that a high quality of decision-making is maintained without implementing a selection tool. Therefore, the benefits of applying a selection model are perceived to be outweighed by the cost and time involved in implementing the model. However, the results are limited by the fact that this is only one example. Field tests at several more small companies are desirable to gain a better understanding of the applicability of the project selection model within small firms. Different companies and different styles of management may produce different field test results. For instance, the importance placed on recording the decision-making process by particular senior managers will have a significant effect on the likelihood of decision support systems being implemented within a firm. Also, in larger companies, using a formal selection process to assist decision-making is likely to have greater benefit than in small firms since larger firms have more decision-makers and thus by default there is more to be gained by aiming to achieve a more consistent decision-making process.

The field test has shown that cost is a barrier to small firms implementing formal project selection techniques. Perceived benefits of such a decision support system are judged to be outweighed by the cost of using a model. Many larger companies already utilise structured project selection decision processes and could therefore adopt the particular model being considered here much more easily than a small firm with more limited financial resources.

One of the advantages of implementing the project selection model is that it allows a record of learning within the company to be kept. Such records are likely to be more valuable in large 
companies than in small firms. In large companies the scope to share decision-making knowledge is greater than in small firms where the number of decision-makers is less. Indeed in the test case here the number of decision makers is one and thus the value of keeping decision making records to share knowledge is very low. This offers an explanation as to why small firms in general and the company participating in this field test in particular are unwilling to invest the time and money to allow the implementation of a hybrid project selection model.

The field test identified a need for engineering management to track $R \& D$ project and portfolio finances more closely. Prompted by the willingness of management to formalise analysis and record keeping of financial aspects of R\&D projects, a simple spreadsheet based tracking method has been developed. The method meets the requirements expressed by engineering management of being quick and easy to use. It clearly displays individual project and overall portfolio finances over time. The method makes it straightforward for management to quickly establish the effect of changes to projects' budgets and time scales to the overall portfolio cash flow.

The company's interest in only formalising financial project aspects is not altogether surprising. Financial models have the most widespread use in large firms. This combined with the reduced value identified of sharing knowledge in small firms compared with large firms explains the greater reluctance of small companies to adopt a hybrid project selection model.

\section{Acknowledgements}

The authors would like to thank the United Kingdom Engineering and Physical Sciences Research Council and also Rotadata Ltd. for supporting this project. 


\section{References}

Coldrick S, Lawson C P, Ivey

P C, Lockwood C, (2002)

Cooper R G, Edgett S J,

Kleinschmidt E J, (1997a)

Cooper R G, Edgett S J,

Kleinschmidt E J, (1997b)

Cooper R G, Edgett S J,

Kleinschmidt E J, (1998)

Cooper R G, Edgett S J,

Kleinschmidt E J, (1999)

Cooper R G, Edgett S J,

Kleinschmidt E J, (2000)

Cooper R G, Edgett S J,

Kleinschmidt E J, (2001)

Cooper R G, Kleinschmidt E J, (1995)
“A Decision Framework For R\&D Project Selection”, IEEE IEMC August 2002.

"Portfolio Management in New Product Development: Lessons from the Leaders-I”, Research Technology Management, Vol. 40, Issue 5, (Sept/Oct 1997). ISSN 08956308.

"Portfolio Management in New Product Development: Lessons from the Leaders-II”, Research Technology Management, Vol. 40, Issue 6, (Nov/Dec 1997). ISSN 08956308.

“Best Practices for Managing R\&D Portfolios”, Research Technology Management, Vol. 41, Issue 4, (July/Aug 1998). ISSN 08956308.

"New Product Portfolio Management: Practices and Performance", Journal of Product Innovation Management, Vol. 16, pp 333-351, (1999)

“New Problems, New Solutions: Making Portfolio Management More Effective”, Research Technology Management, Vol. 43, Issue 2, (Mar/Apr 2000). ISSN 08956308.

"Portfolio Management for New Product Development: Results of an Industry Practices Study”, R\&D Management, Vol. 31, Issue 4, (Oct 2001). ISSN 00336807.

“Benchmarking Firm's New Product Performance and Practices”, Engineering Management Review 23, (1995). 
Ferguson D (1997)

Lockwood C (1999)

Matheson D, Matheson J E, Menke M M, (1994)

Menke M M, (1997a)

Menke M M, (1997b)

Moore J R Jr., Baker N R, (1969)

Osawa Y, Murakami M, (2002)

Smout (1995)

Stillman H M, (1997)
“The Development of Air-Cooling Techniques for Fast Response Pressure Transducers in High Temperature Environments”, PhD Thesis, Cranfield University, (1997).

"Comparison of Average-Passage Equation Closures Through Simulation of Single and Multi-Row Axial Compressors; The Limitations of Using A Commercial CFD Code”, PhD Thesis, Cranfield University, (1999). “Making Excellent R\&D Decisions”, Research Technology Management, Vol. 37, Issue 6, (Nov/Dec 1994). ISSN 08956308.

“Essentials of R\&D Strategic Excellence”, Research Technology Management, Vol. 40, Issue 5, (Sept/Oct 1997). ISSN 08956308.

“Managing R\&D for Competative Advantage", Research Technology Management, Vol. 40, Issue 6, (Nov/Dec 1997). ISSN 08956308.

“An Analytical Approach to Scoring Model DesingApplication to Research and Development Project Selection” IEEE Transactions on Engineering Management, Vol EM-16, No. 3, (Aug 1969).

"Development and Application of a New Methodology of Evaluating Industrial R\&D Projects”, R\&D Management, Vol. 32, Issue 1, (Jan 2002). ISSN 00336807.

"The measurement of near wall flows using pneumatic wedge probes.”, PhD Thesis, Cranfield University, (1995).

"How ABB Decides on the Right Technology Investments”, Research Technology Management, Vol. 40, Issue 6, (Nov/Dec 1997). ISSN 08956308. 